\title{
Anemia Falciforme: Concepção do cuidador familiar sobre a doença e seu tratamento em um Município do Maranhão
}

Falciform Anemia: Conception of the family caregiver about the disease and its treatment in a City in Maranhão

Anemia Falciforme: Concepción del cuidador familiar de la enfermedad y su tratamiento en un Municipio de Maranhão

Helen Lucy Maria Rocha Barroso ORCID: https://orcid.org/0000-0001-8537-7808

Universidade Estadual do Maranhão, Brasil E-mail: helenlucy.hl40@gmail.com

Alana Jéssyca Costa Sipaúba

ORCID: https://orcid.org/0000-0003-0127-118X Faculdade de Ciências e Tecnologias do Maranhão, Brasil E-mail: alanacolinas@hotmail.com

Thátila Larissa da Cruz Andrade ORCID: https://orcid.org/0000-0002-8030-3516

Universidade Estadual do Maranhão, Brasil E-mail: thatilaandrade@gmail.com

Josielen Barroso Leal Maciel

ORCID: https://orcid.org/0000-0001-9237-2466

Universidade Estadual do Maranhão, Brasil E-mail: usuariodavid52@gmail.com

Klécia de Sousa Marques da Silva ORCID: https://orcid.org/0000-0001-5331-8934

Universidade Federal do Maranhão, Brasil E-mail: kleciamarques19@gmail.com

Suélly Mayara Rodrigues da Fonseca ORCID: https://orcid.org/0000-0003-0822-0764 Universidade Estadual do Maranhão, Brasil E-mail: suellyenfermag@gmail.com Gardênia Monteiro Batista ORCID: https://orcid.org/0000-0002-1874-5225 Universidade Ceuma, Brasil E-mail: gardenia_mc@hotmail.com

\begin{abstract}
Resumo
Introdução: A anemia falciforme - AF é uma alteração genética, pois acontece a mutação da hemoglobina, designada como hemoglobina S ou HbS. Objetivo: conhecer a concepção do cuidador familiar do portador da AF, sobre a doença e seu tratamento no município de Colinas. Metodologia: Trata-se de um estudo na forma descritiva com abordagem qualitativa, realizado no município de Colinas - MA, no período de maio a junho de 2019. Onde utilizouse como instrumento de coleta de dados, questionários semiestruturados. Resultados e Discussão: Foram entrevistadas oito (8) responsáveis pelos portadores de anemia falciforme, dos oito (8), seis (6) é a mãe do portador, um (1) é a avó e um (1) é a bisavó da criança, idade de 25 a 64 anos. Ao questionar sobre a etnia $75 \%$ se consideraram pardos, $12,5 \%$ negros e $12,5 \%$ brancos; sobre a renda familiar 12,5\% declararam receber dois salários mínimos, $62,5 \%$ vivem com um salário mínimo e $25 \%$ vivem com menos de um salário mínimo; ao indagar sobre a escolaridade $50 \%$ não concluíram o ensino fundamental, $25 \%$ têm ensino médio incompleto e $25 \%$ concluíram ensino médio; sobre a quantidade de filhos 37,5\% tem três (3) filhos, 37,5\% possuem dois (2) filhos e 25\% apenas um (1) filho. Conclusão: No presente estudo foi analisado que o município não fornece todos os núcleos que integra o tratamento da siclemia.

Palavras-chave: Anemia falciforme; Genética médica; Cuidador familiar.
\end{abstract}

\section{Abstract}

Introduction: Sickle cell anemia - AF is a genetic alteration, since hemoglobin mutation occurs, designated as hemoglobin $\mathrm{S}$ or $\mathrm{HbS}$. Objective: to know the conception of the family caregiver of the PA patient about the disease and its treatment in the city of Colinas. Methodology: This is a descriptive study with a qualitative approach, carried out in the municipality of Colinas - MA, from May to June 2019. Where semi-structured questionnaires were used as 
a data collection instrument. Results and Discussion: Eight (8) responsible for sickle cell anemia patients were interviewed, of the eight (8), six (6) is the mother of the carrier, one (1) is the grandmother and one (1) is the greatgrandmother of the child, age 25 to 64 years. When asked about ethnicity, $75 \%$ considered themselves brown, $12.5 \%$ black and $12.5 \%$ white; on family income $12.5 \%$ declared to receive two minimum wages, $62.5 \%$ live on one minimum wage and $25 \%$ live on less than one minimum wage; when asking about education, $50 \%$ have not completed elementary school, $25 \%$ have incomplete high school and $25 \%$ have completed high school; on the number of children $37.5 \%$ have three (3) children, $37.5 \%$ have two (2) children and $25 \%$ only one (1) child. Conclusion: In this study, it was analyzed that the municipality does not provide all the centers that integrate the treatment of sickle cell disease.

Keywords: Sickle cell anemia; Medical genetics; Family caregiver.

\section{Resumen}

Indroducción: La anemia de células falciformes - AF es una alteración genética, ya que se produce una mutación de la hemoglobina, denominada hemoglobina S o HbS. Objetivo: conocer la concepción del cuidador familiar del paciente AP sobre la enfermedad y su tratamiento en la ciudad de Colinas. Metodología: Se trata de un estudio descriptivo con enfoque cualitativo, realizado en la ciudad de Colinas - MA, de mayo a junio de 2019. Donde se utilizaron cuestionarios semiestructurados como instrumento de recolección de datos. Resultados y Discusión: Se entrevistaron ocho (8) pacientes responsables de anemia falciforme, de los ocho (8), seis (6) es la madre del portador, uno (1) es la abuela y uno (1) es el tatarabuelo. -abuela del niño, de 25 a 64 años. Cuando se les preguntó sobre la etnia, el $75 \%$ se consideró moreno, el 12,5\% negro y el 12,5\% blanco; de los ingresos familiares, el 12,5\% declaró recibir dos salarios mínimos, el $62,5 \%$ vive con un salario mínimo y el $25 \%$ vive con menos de un salario mínimo; al preguntar sobre educación, el $50 \%$ no completó la educación primaria, el 25\% tiene educación secundaria incompleta y el 25\% la educación secundaria completa; sobre el número de hijos el 37,5\% tiene tres (3) hijos, el 37,5\% tiene dos (2) hijos y el $25 \%$ solo un (1) hijo. Conclusión: En el presente estudio se analizó que el municipio no cuenta con todos los centros que integran el tratamiento de la anemia falciforme.

Palabras clave: Anemia de células falciformes; Genética médica; Cuidador familiar.

\section{Introdução}

A Anemia Falciforme (AF) é uma mutação genética herdada dos pais diferente dos indivíduos normais que herdam o caráter AA, as pessoas falcêmicas herdam de cada genitor uma hemoglobina S e por isso elas são SS denominado AF (Brasil, 2015c).

Esta condição é caracterizada por uma alteração nos glóbulos vermelhos, que perdem a forma arredondada e elástica, assim adquirindo o aspecto de foice (de onde vem o nome falciforme) e endurecem, sendo o principal responsável pela fisiopatologia da AF, pois dificulta a passagem do sangue pelos vasos de pequeno calibre e a oxigenação dos tecidos (Fonseca, 2019).

Conforme os dados que constam na literatura, há uma maior incidência em povos africanos. No entanto, não deve ser considerada uma doença de raça negra, pois o povo do Mediterrâneo, Índia, Oriente Médio também tem predisposição para manifestação do gene, porém com menores proporções (Brasil, 2015b).

Segundo o Ministério da Saúde - MS (2015c), "os sintomas podem começar aparecer ainda no primeiro ano de vida, mostrando a importância do diagnóstico precoce como principal medida de impacto positiva na assistência de qualidade às pessoas com a doença." Esses sintomas ocorrem devido à diminuição do fluxo sanguíneo nos capilares venosos, causando a estase venosa e a hipóxia, dando origem as crises dolorosas agudas, anemia crônica, morte de tecidos e órgãos. Com isso, o individuo com AF se torna mais propício a infecções, sequestro esplênico, a síndrome torácica aguda e o priapismo (Brasil, 2014a).

Mesmo sendo intensas as manifestações, elas podem ser prevenidas e tratadas, desta forma, são garantidas qualidade de vida e longevidade, por meio de protocolos são definidos os procedimentos adequados a serem usados (Brasil, 2015c).

A AF é considerada como preocupante problema de saúde pública mundial com um largo impacto na mortalidade da população afetada. Das regiões que mostram uma alta taxa de incidência e prevalência da enfermidade destacam-se as regiões norte e nordeste, onde as prevalências são de $6 \%$ a 10\%, já nas regiões sul e sudeste estas taxas são de 2\% a 3\% (Brasil, 
2015b). Contudo, a mortalidade em crianças de até 5 (cinco) anos de vida sem cuidados é de $80 \%$ (vida média de 8 anos) e tendo os cuidados adequados é de 1,8\% (vida média de 45 anos) (Brasil, 2015c). Sendo que, a inexistência de informações nos atestados de óbito, a ausência de cadastros informatizados nos centros de referências e hemocentros e a existência de população sem diagnóstico, ficando assim sem dados consistentes da letalidade da doença falciforme.

Além disso, a AF tem repercussão em vários aspectos da vida da pessoa com este diagnostico, como a interação social, relações conjugais, familiares, educação e emprego (Brasil, 2014a). Vale ressaltar sobre a importãncia do diagnóstico precoce, pois é de suma importância para indetificação, registro e acompanhamento dos casos. Podendo contribuir de forma ativa, para que ocorra o planejamento e uma organização da rede de atenção íntegral à DF, assim como para melhoria da qualidade de vida dos pacientes (Araújo et al., 2020).

Tratar o paciente com AF consiste em apresentar modalidade de tratamento que resulte em uma melhor qualidade de vida, assim como média de sobrevida prolongada. Tais condições podem ser alcançadas através da terapia farmacológica, terapia de transfusão sanguínea e terapia de apoio às quais necessitam de profissionais qualificados, para o atendimento aos indivíduos com a doença, que em muitas ocasiões não recebem cuidados adequados pelo desconhecimento dos profissionais no manejo da doença (Brasil, 2015c).

A dificuldade de acesso, assim como o excesso de fragmentação no cuidado provocam a descontinuidade da assistência, a perda de vínculo com o profissional de saúde, possibilitando consequências desfavoráveis ao tratamento, bem como a baixa adesão das pessoas com doença falciforme (Brasil, 2015c).

A pesquisa desenvolveu-se seguindo a seguinte questão norteadora: Qual a concepção do cuidador familiar a respeito da AF e o seu tratamento?

O interesse pelo tema foi despertado pelo conhecimento a respeito dos impactos da doença que repercutem não só no portador, mas racionam consequências relevantes também na vida dos familiares.

Tendo por base os agravantes da anemia falciforme na qualidade de vida dos portadores e dos seus cuidadores, o presente estudo teve como objetivo principal, conhecer a concepção do cuidador familiar do portador da AF, sobre a doença e seu tratamento no município de Colinas.

Os objetivos específicos foram: Discorrer sobre o conhecimento do cuidador familiar em relação aos cuidados com portador da AF; relatar a concepção do cuidador familiar sobre a AF; expor a experiência do cuidador familiar relacionada ao portador da AF sobre assistência terapêutica no município e descrever suas experiências nos momentos de crise.

\section{Metodologia}

Trata-se de um estudo na forma descritiva com abordagem qualitativa, realizado no município de Colinas - MA, no período de maio a junho de 2019. Os participantes foram selecionados a partir dos seguintes critérios de inclusão e exclusão: os portadores de AF, assim como, os cuidadores familiares devem possuir cadastro no centro de referência para doenças falciformes do município em estudo, que possibilite contato para participação na pesquisa, além de residir no munícipio.

A população maranhasse estimada para 2019 foi de 7.075.181 habitantes segundo o Instituto Brasileiro de Geografia e Estatística - IBGE e a cada 1.400 nascidos vivos por ano um (1) é diagnosticado com AF (BRASIL, 2014a). Em Colinas - MA a população estimada para 2019 era de 41.178 (IBGE) tendo 26 portadores da AF no ano de 2018, cadastrados na Agencia Trasfusional da cidade, mas, somente 16 são do município.

Foram encontradas dezesseis (16) pacientes cadastrados no centro de referência e destes teve-se a possiblidade de entrevistar oito (8) responsáveis pelo cuidado ao portador de AF (mãe, avó e bisavó), devido à escassez de informações no cadastro de alguns pacientes, impossibilitou-se a comunicação com os mesmos, desse modo, foram nove (9) crianças 
diagnosticadas com AF, na qual os cuidadores participaram do estudo, dentre elas duas (2) irmãs. Sendo que, a faixa etária dos participantes foi de 25 a 64 anos.

A coleta de dados se deu em duas fases: primeiro foi preciso uma busca de dados nos prontuários disponíveis na Agência Transfusional de Colinas (HEMOMAR) para identificar os portadores. A segunda fase foi à busca destes pacientes em sua residência acompanhada do Agente Comunitário de Saúde - ACS da área em que o paciente reside.

Foi utilizado como instrumento de coleta de dados, questionários semiestruturados. Sendo utilizado gravador digital, possibilitando a melhor obtenção de dados com autorização previa dos participantes garantindo o anonimato dos entrevistados.

Para análise dos dados obtidos na etapa de coleta, o processo de investicação do material de campo recorreu aos pressupostos da análise do conteúdo da temática. Baseado na visão de Bardin (2009), a análise de conteúdo temática deve ter como ponto de partida uma organização. As diversificadas fases da análise de conteúdo organizam-se em torno de três polos: a pré- análise, a exploração do material; e, por fim, o tratamento dos resultados: a inferência e a interpretação.

Os dados obtidos pelas entrevistas foram digitados e transcritos na integra pelas próprias pesquisadoras e os entrevistados identificados com nomes fictícios, garantindo o anonimato conforme preconiza a legislação sobre pesquisas envolvendo seres humanos.

A pesquisa foi aprovada pelo Comitê de Ética em Pesquisa - CEP de número: 3.235.488, os participantes assinaram o Termo de Consentimento Livre e Esclarecido - TCLE, que continha informações sobre o estudo, além de garantir os quatro referenciais básicos da bioética: autonomia, não maleficência, beneficência e justiça, exigidos de acordo com as orientações da resolução $\mathrm{n}^{\circ} 510$ de 7 de abril de 2016 e acompanhada de observações gerais sobre o entrevistado no momento do depoimento.

\section{Resultados e Discussão}

Durante a pesquisa foram entrevistados oito (8) responsáveis pelos portadores de AF, dos oito (8) entrevistados; seis (6) são as mães dos portadores, um (1) é a vó e uma (1) bisavó da criança, com idades entre 25 a 64 anos. Ao questionar sobre a etnia $75 \%$ se consideraram pardos, $12,5 \%$ negros e $12,5 \%$ brancos; sobre a renda familiar $12,5 \%$ declararam receber dois salários mínimos, $62,5 \%$ vivem com um salário mínimo e $25 \%$ vivem com menos de um salário mínimo; ao indagar sobre a escolaridade 50\% não concluíram o ensino fundamental, $25 \%$ têm ensino médio incompleto e $25 \%$ concluíram ensino médio; sobre a quantidade de filhos 37,5\% tem três (3) filhos, 37,5\% possuem dois (2) filhos e $25 \%$ apenas um (1) filho.

Em relação aos irmãos dos pacientes que foram diagnosticados com $\mathrm{AF}$ 87,5\% não tem o traço $\mathrm{HbS}$, enquanto isso 12,5\% possuem os traços. O sexo do portador em sua maioria é do sexo masculino 56\% e $44 \%$ feminino; a idade $11 \%$ tem 3 anos de idade, $78 \%$ tem de 6 a 10 anos e $11 \%$ tem 13 anos, dados estes que conferem com o estudo de Vieira (2016).

Em concordância com o MS (2015), para que ocorra o nacimento de um criança com a doença falciforme é preciso que ela receba do pai e da mãe a herança do gene com a alteração, podendo ser 50\% com o gene Hb AS (traço normal) e $25 \%$ com o gene $\mathrm{Hb}$ SS (doença falciforme), uma vez que a cada gestação, esse casal terá $25 \%$ de probalidade de ter um filho com gene normal.

Perante a análise das falas dos entrevistados, surgiram três categorias centrais: Impacto da Doença; Assistência Terapêutica e Vinculo Social. E serão apresentadas e discutidas a partir de agora.

\subsection{Impacto da Doença}

A AF por ser uma doença crônica provoca um grande impacto sobre a vida da família, especialmente quando se trata de crianças e adolescentes, requerendo cuidados por toda a vida, via de regras, produzidos no âmbito familiar (Silva et al., 2013). Visto que, a prevalência do traço falciforme mostra a importância da execução de políticas públicas relacionadas ao acompanhamento, orientação genética e assistência integral à saúde das pessoas portadoras de traço e de AF (Vieira, 2016). 
Quando acontece a descoberta do diagnóstico de doença crônica na infância é considerado um evento de forte impacto emocional, o que pode ser entendido como um diagóstico iminente de morte, na qual ocasionará a perda do filho, que antes era visto como uma criança saudável (Leite et al., 2015).

Ao serem questionadas sobre a suas reações ao descobrirem a doença e sua primeira reação, foi visto um misto de emoções, em alguns relatos não sabiam nem mesmo de que doença se tratava e só depois do diagnóstico tiveram o devido conhecimento sobre a mesma.

Segundo Ataíde (2017, p. 4), "além do sofrimento psíquico e das diversas adaptações, mudanças, inseguranças e limitações que são provocadas pelo diagnóstico da doença falciforme, há também os componentes de ordem social, tais como desestruturação familiar, poder aquisitivo baixo e desemprego, que aumentam ainda mais o impacto do diagnóstico." Como podemos perceber nas seguintes falas:

"[...] Quando chegou o teste e o resultado foi positivo para anemia falciforme me deu um desespero [...]" (Motivação).

"Eu fiquei assim desesperada, né? Porque nesse tempo ela (médica), ela falou, não foi ela que falou, uma mulher que trabalha no Macieira (Hospital Carlos Macieira), até hoje eu tenho nojo dela dizendo: - que ela tinha essa doença e quem tinha essa doença não passava dos sete anos. Ai eu fiquei doida chorando desesperada, ai até hoje eu to ai lutando com ela [...]" (Guerreira).

"Sei nem dizer direito o que senti na hora, quando o médico me dizendo que doença era e que não tinha cura. Eu fiquei muito triste, entende? Não sabia nem o que fazer." (Cuidadora).

A mulher, que divide os papéis de mãe e trabalhadora, possui seu lado maternal e cuidador revelado de maneira intensa, abrindo mão de outros papéis para dedicar-se exclusivamente a seu filho doente (Guimarães; Miranda \& Tavares, 2009). A vida da mãe muda, de forma brusca, pois não se trata de uma criança que pode brincar como as outras são dependentes de cuidado e atenção de forma integral, isto é demostrado pelos relatos abaixo:

"Assim, tem que ter muito cuidado de não deixar elas, sair correndo ai na rua, que nem estes meninos normal, elas não, elas brincam aqui mesmo no quintal, tenho muito cuidado, pra elas não andarem correndo nem pulando por causa das crises delas, pra não sentir muita dor. Ai tem que cuidar." (Guerreira).

"Sabe, mudou né? Pois não é uma criança como as outras [...] toda criança adoece, mas quem tem essa doença é diferente, ele ta aqui normal e do nada tem as crises, ai tem que sair com ele pro hospital. Ai tem que ta em São Luiz pras consultas dele $[\ldots]$ tem que cuidar dele direto [...]" (Esperança).

Durante a pesquisa as entrevistadas demostraram total cuidado com o portador para não se machucar e não fazer bastante esforço, pois temem uma eventual crise e acidentes podendo ocorrer uma fratura os deixando mais debilitados.

Os cuidados e o tratamento da doença falciforme acarretam aumentos nos gastos, o que representa uma das principais dificuldades enfrentadas pela família. Em virtude das dificuldades financeiras, as mães expressam receio de não conseguir manter os cuidados exigidos com a criança (Ataide, 2017).

Uma das entrevistadas demostra que o seu cotidiano mudou devido a grande quantia de medicação que o portador utiliza e este fato lhe aflige por muitas vezes, não saber se vai conseguir comprar o medicamento. Como se percebe na fala abaixo:

"Mudou e foi muito! Obrigado todos os meis comprar mei mundo de remédio pra ele, mei mundo, com ajuda só de Deus e do aposentim que eu tenho... nem que eu passe fome os remédios tenho que comprar tudo." (Fé).

O cuidador em sua maioria é a mãe que acompanha nas chamadas "crises", que providencia marcação de consultas, exames, medicamentos e ainda busca entender o que está acontecendo com suas filhas (os) diante do desconhecimento da doença principalmente no que se refere aos profissionais de saúde (Pimentel, 2019).

Foram feitos alguns questionamentos sobre a reação da cuidadora e se sentiram incapazes de realizar o cuidado diante 
de uma crise, a maioria tem em mente o que fazer, mas houve momentos que ficaram estagnadas sobre o que deveria ser feito naquele momento.

Sobre a reação diante de uma crise, observam-se as falas abaixo:

"Eu de primeiro levava pro hospital, não levo mais não, porque levo ele e trago do mesmo jeito [...] vou tratando aqui, passo aguardente nas pernas dele [...]" (Fé).

"Eu dou o remédio pra dor que o médico passa pra dor, sabe? Tenho cuidado com ela quando sente alguma coisa [...] Eu fico preocupada, com medo de acontecer algo, mais grave, ai se não melhora com a dipirona eu levo pro hospital" (Batalhadora).

As mães têm dificuldade de cuidar do filho após o diagnóstico por desconhecerem a doença, mas, após as consultas e o convívio com o filho, elas se adaptaram à situação e passaram a ter menos dificuldades para exercer o cuidado (Lessa, 2012). Ao questionar sobre o sentimento de incapacidade de lidar com as crises, a grande maioria relata que, em algum momento ficaram sem saber como lidar com os episódios de crise. O que se comprova a seguir nas falas das entrevistadas:

“Já, já porque um tempo desses teve uma crise, levei pro médico deram uma injeçãozinha, mandaram vim me embora e o menino chorando, o menino chorando [...] passei quatro dia com ele chorando [...]” (Fé).

"É difícil não se sentir assim, você ver seu filho doente, sentindo dor e você sem poder fazer nada, dão o remédio pra ela, mas ai você sabe que daqui uns dias ela vai sentir a mesma dor, porque essa doença não tem cura, é difícil, mas estou enfrentando essa doença com ela" (Batalhadora).

A doença crônica acarreta um grande impacto no cuidador familiar do paciente, os sentimentos que o cuidador tem e que se tornam importantes na relação paciente-doença, em sua maioria geralmente é negligenciado pelos profissionais de saúde. Conhecer e ampliar os aspectos positivos e as vivências agradáveis, decorrentes do contato com a doença constitui uma possibilidade de cuidar do doente crônico e de seu familiar (Ferreira et al., 2012).

Desta maneira, fica evidente que a AF compromete a qualidade de vida, não apenas do portador, como também dos membros familiares, o que de certa forma acaba privando o paciente diagnóticado com a patologia em discussão. Demonstrando de certa forma, a real importância de um cuidado especial voltado para à pessoa acometida com doença falcêmica (Araújo et al., 2020).

\subsection{Assistência Terapêutica}

No caso da AF, para que ocorra o atendimento precoce, é preciso que as pessoas estejam informadas sobre a existência da doença e consigam identificá-la (Figueiredo et al., 2014). Durante a pesquisa foi constatado que 37,5\% (3) descobriram a doença com um ano de idade, 37,5\% (3) com menos de um ano, 12,5\% (1) de 2 a 5 anos e apenas 12,5\% (1) ainda recém-nascido. A demora na descoberta da doença foi percebida devida certas dificuldades relatadas por 25\%: por falta de material na unidade de realização do teste, por demora da chegada do resultado, por falta de informação da sua importância e muitas vezes por não haver a procura do responsável da criança para a realização do teste quando o material estava em falta na maternidade.

Evidenciou-se que o cuidador familiar possui conhecimentos dos cuidados preventivos a serem prestados aos filhos. Porém, são poucos orientados sobre os exercícios físicos, que os portadores de AF, assim como, os sinais que podem ser percebidos na crise de sequestro esplênico, sendo importante que a equipe oriente os familiares a respeito destes sinais, pois suas repercussões podem agravar a saúde da criança, podendo levar a óbito (Lessa, 2012).

Os cuidados com o paciente falcêmico devem ser constantes, é importante que o cuidador familiar tenha o conhecimento a respeito de fatores que podem causar a crise ou evitar. Os entrevistados demostraram certo conhecimento sobre os cuidados que devem ter com os pacientes, isto é importante para uma sobrevida de qualidade. É possível identificar 
esta concepção nas falas asseguir:

"Os cuidados é direto, sabe? Dar os remédios direito e não deixar faltar, fazer a comida do jeito que ela pode comer, porque quem tem essa doença não pode comer toda coisa, entende? Ai tem que ter esse cuidado, dar muita água, suco essas coisa" (Confiança).

"Os cuidados que tenho com ele é o que me dizem pra mim ter quando vou nas consulta, que é dar bastante água, não deixar comer porcaria, essas coisinhas que criança gosta de tá comendo ele não pode” (Motivação).

Para Rodrigues et al., (2018):

"existe uma necessidade da atuação do enfermeiro na orientação das mães para a administração segura e correta dos fármacos no domicílio, a fim de reduzir complicações relacionadas com absorção do medicamento, supressão terapêutica e exposição indevida dos cuidadores à droga."

Desse modo, é de suma importância que os profissionais de saúde orientem os cuidadores dos portadores de AF, quanto a dosagem, horário dos medicamentos a serem utilizados, assim como, sobre a importância da manutenção do tratamento preconizado e de uma alimentação de qualidade, a qual se adeque ao diagnóstico do paciente.

De acordo com Rodrigues et al., (2018), "é essencial realizar a terapia medicamentosa no domicílio para crianças e adolescentes portadores de DF, o que vai colaborar para que ocorra a continuidade da assistência prestada, assim como, a melhora do prognóstico." O cuidador familiar deve receber informações básicas sobre a medicação utilizada pelo paciente. Foi constatado que grande parte dos entrevistados tem conhecimento de qual a medicação utilizada pelo portador de AF, como segue asseguir:

"Desde os 5 ou 6 meses ele toma benzetacil, hoje em dia que ele não toma mais, que ele parou com 4 anos, mas, a benzetacil era de 21 em 21 dias, que ele tomava [...] Ele toma complexo B, ácido fólico, agora estou dando cálciovita pra ele" (Renovação).

“Ela usa, como é nome? É enrolado o nome... há é a hidroxiureia e quando sente dor eu dou a dipirona” (Batalhadora).

Assim sendo, as hospitalizações de repetição, em que a família vivencia os procedimentos invasivos na criança como as venopunções e administrações de medicamentos, geram o sofrimento e o medo da perda do filho (Gesteira; Bousso \& Rodarte, 2016).

Segundo os dados encontrados na pesquisa em questão, o cuidador familiar demostrou um misto de sentimentos: aflição, tristeza, desanimo e incerteza do futuro. Durante este momento, é importante que o profissional tenha sensibilidade de garantir apoio emocional, dando conforto durante o procedimento, para que a internação não seja um momento só de sofrimento. Onde ficou evidente nas seguintes indagações abaixo:

"Já, aconteceu muito ai a gente assim sem jeito desanimada" (Guerreira).

"Quando acontece, eu fico assim triste de ver ela ali doente [...] é ruim ver o filho da gente doente" (Confiança).

Durante a hospitalização é preciso que o profissional esteja preparado para fornecer cuidado ao paciente com AF, sabendo avaliá-los considerando suas necessidades e suas trajetórias de vida com a doença, que implica em inúmeras internações ao longo da vida (Carvalho et al., 2016).

\subsection{Vínculo Social}

Conforme os presentes autores, a qualidade de vida dos portadores de AF, são consideradas como desfavoráveis, quando relacionada aos aspectos físicos e sociais (Limaet al., 2019). Por consequência as pessoas falcemicas não podem fazer atividades simples do dia-a- dia, devido os recorrentes sinais e sintomas que as impedem (Brito, 2018). 
A doença traz um impacto significativo no exercício das atividades principais, da infância à idade adulta. Deixando "marcas" desde o nascimento e estendendo até o fim da vida, ocasionando dificuldades que vão se articulando a outras e criando repercussões a curto, médio e longo prazo (Rosa \& Martin, 2019).

As crianças do estudo de acordo com os seus cuidadores não possuem nenhum tipo de limitação física, porém durante a análise das falas percebeu-se uma limitação tanto física como social; pois existe uma limitação do portador em participar das mesmas brincadeiras que as crianças "normais". O que ficou visível nas falas abaixo:

"Não, ele tinha um problema na perna, mas agora não tem, mas não, ele esquece a perna se ele ficar sem tomar a remédio ele fica doente." (Fé).

"Não, os médicos me recomendaram não deixar ele andar muito no sol. Ficar no sol, se expor ao sol. E nada de brincadeira pesada, cuidado com acidentes, por essa questão do osso, se ele chegar a quebrar não sabe se volta pro lugar". (Motivação).

"Nenhuma, assim ele não pode ficar brincando de correr essas brincadeiras que todo menino brinca, tem que brincar por que se não ele tem as crise, sabe? Ai pra ele não ter crise ele brinca, mas dentro de casa, sem ta correndo no sol quente pra lá e pra cá.” (Esperança).

Com o fato de o filho possuir uma doença crônica as mães possuem maior probabilidade em desenvolver sentimentos de revolta e solidão muitas vezes por não se sentirem aceitas pela sociedade devido à doença do filho (Lopez \& Stuhler, 2008).

Durante a exploração das falas, as participantes demostraram receber apoio e orientações "empíricas" do meio social, a participante Esperança durante toda a entrevista demostrou um receio de falar sobre a doença e a sua fala confirma uma insatisfação em possuir um filho com AF, concluindo assim, que a sociedade não tem "bons olhos" sobre a doença do filho. $\mathrm{O}$ que é perceptível nas repostas a seguir:

"Não é que eu goste de falar sobre a doença, mas me desculpe pelo meu jeito, mas pra mim é muito chato falar a respeito da doença falciforme.” (Esperança).

"Assim pelo menos daqui (refere à rua em que mora) todo mundo só me orienta, alguns falam: num sei o que é bom, uma chá de num sei o que é bom, dar pra ele, ou as vezes as pessoas da família do meu marido (nome do filho) ta meio amarelinho da cálcio pra ele, dar alguma coisa pra ele, faz uma comida diferente, sempre me orienta as pessoa, sempre me aconselham a cuidar dele direitinho" (Renovação).

$\mathrm{Na}$ doença falciforme, assim como em outras doenças crônicas, os aspectos psicossociais afetam diretamente a adaptação emocional e social das pessoas que as possuem, durante todo o ciclo vital (Felix; Souza \& Ribeiro, 2010).

De acordo com os mesmos autores o paciente demostra sentimentos de revolta/tristeza isto é associado às crises dolorosas apresentadas diversas vezes durante o ano.

Conforme os dados da pesquisa, os portadores têm reações divergentes durante as crises dolorosas, $78 \%$ se isolam e não informam a seu cuidador o que estão sentido, pois existe uma preocupação da parte deles em alamar o cuidador e passar por eventuais procedimentos, a partir desses dados é visto a importância de um olhar atento do seu responsável e $22 \%$ dizem de imediato o que está sentido pra buscar um cuidado adequado.

"Ele chama pra ir pro hospital - Bora po pital mãe, ele diz" (Fé).

"Nam, elas ficam pra li tristizinha, elas não querem contar pra não preocupar a gente [...] ai eu já conheço, elas já ficam por ali e sem querer dizer ai a gente já conhece" (Guerreira).

"Sabe ele fica com a expressão triste, sabe? E não fala nada pra mim, só que quem é mãe sabe quando o filho não está bem, eu pergunto, mas, ele não quer falar pra gente [...] ele sente medo das agulhas também" (Cuidadora).

No decorrer da investigação, captou-se que a principal rede de apoio é a família, ficandando perceptível nas falas asseguir: 
"Minha cunhada, minha sogra e meu marido, meu marido fala cuida do D. sabe que D. é doentinho" (Renovação) e outra forma de apoio é os amigos que neste momento se tornam muito importante, o que é visto na seguinte fala: "Minha família me ajuda bastante, nos cuidados dela, tem as meninas aqui da rua que me ajudam também quando eu preciso, não é direito que elas podem, mas quando vem é bom" (Confiança).

O olhar com empatia se tona muito importante ao cuidar de uma criança com doença crônica, principalmente no ambiente em que a mesma recebe os cuidados. O que é evidenciado nas afirmação posterior:

"No hospital, porque assim todo mundo conhece a gente, na hora que chegamos lá, as enfermeiras atende a gente bem e vem conversar" (Guerreira).

A vida escolar faz parte do vinculo social e extremamente importante para a formação da sociedade, porém para o portador de $\mathrm{AF}$ existe certas dificuldades devido às complicações advindas da doença.

De acordo com Rodrigues, 2018 apud Gonçalves; Cordeiro \& Silva, 2018:

"O cérebro dos portadores de AF pode apresentar alterações que acarretam prejuízos no desempenho acadêmico e escolar nesses educandos como o AVC, lesões isquêmicas, infartos silenciosos e até deficiência no desenvolvimento das funções cognitivas em decorrência das alterações na oxigenação desse órgão".

A AF interfere diretamente no cotidiano dos portadores, e as principais consequências desta doença é a dor que esses pacientes apresentam durante o período das crises vaso oclusiva (Gonçalves; Cordeiro \& da Silva, 2018).

Quando questionados sobre as dificuldades na ingressão escolar foi assegurado que a única interferência é a dor, e devido este fator passam diversos dias sem frequentar a escola. Segue abaixo os argumentos:

"Assim, quando elas sentem muitas dores, passam dias sem ir à escola" (Guerreira). "Não, pelo contrario, é o mais inteligente de todos [...]" (Renovação).

"Ela vai bem nos estudos o negocio é quando ela sente dor nas pernas, sente alguma coisa na escola ai tem que vim pra casa e as vezes fica um bom tempo sem ir, ai dificulta um pouco" (Batalhadora).

A cerca do falecimento devido a $\mathrm{AF} 25 \%$ teve algum familiar que faleceu e $75 \%$ relatam que não. O portador de anemia falciforme vem falecer antes da vida adulta e mesmo que venha chegar a esta fase as características da doença pode interferir de forma direta em sua vida social, profissional e acadêmica, ao serem questionados sobre o anseio do futuro do portador demostraram desesperança de um futuro promissor e buscam um amparo na crença religiosa. $\mathrm{O}$ que se constata nas falas a seguir:

"A gente pensa tanta coisa, mas só que eu, assim num futuro é que minhas crianças cresçam né? É tudo que eu peço a Deus, mesmo dizendo que quem tem essa anemia não tem muito tempo todo dia eu peço a Deus". (Guerreira).

"Assim, a gente deseja tudo que é de bom pro filho da gente, que tenha um ótimo futuro, mas quem tem essa doença é difícil viver muito tempo, é o que dizem, eu espero que minha filha tenha um bom futuro sem sofrimento, mas essa doença não deixa" (Confiança).

O importante é viver o agora, principalmente quem cuida de um portador de doença crônica que é a siclemia, devido o fator eminente do óbito ainda na infância é importante que o cuidador saiba lidar com esta situação dando o máximo de afeto possível. Também é relevante que haja uma rede de apoio para ambos, sendo composta por familiares, amizade e da equipe de enfermagem durante o atendimento.

\section{Conclusão}

Verificou- se que existe certa dificuldade para a efetuação do teste de triagem neonatal biológico "teste do pezinho", hora por falta de material na unidade de realização do teste, por demora da chegada do resultado, por falta de informação da 
sua importância e muitas vezes por não haver a procura do responsável da criança para a realização do teste quando o material está em falta nos serviços de saúde.

Foi afirmada a importância da promoção de conhecimento sobre a orientação genética para o portador do traço falciforme, fornecendo entendimento sobre a possibilidade de gerar um portador da AF.

No presente estudo, foi analisado que o município não fornece todos os núcleos que integra o tratamento da siclemia, fazendo com que o cuidador familiar busque o tratamento na capital São Luís, para que isto aconteça é preciso que ele procure os direitos garantidos pelo tratamento fora de domicílio - TFD, nesta busca gera-se transtornos desde a marcação da consulta até sua realização.

Em conformidade com a pesquisa, o principal cuidador é a mãe, que devido a AF ser uma doença crônica e ter a necessidade de cuidados constantes em grande parte ela deixa de lado o cuidado pessoal, esquecendo da sua própria pessoa, se doando integralmente para a realização dos cuidados com o filho doente.

Ficou evidente no decorrer da pesquisa, que o cotidiano da criança diagnosticada com HbSS é totalmente divergente de uma criança "saudável", a doença implica em diversas restrições: alimentar, física, entre outras, que a impede "de ser criança", tendo impacto por toda sua vida. Não somente a vida do portador, mas, de toda a família, em aspectos emocionais, financeiros e sociais.

O sintoma que mais afeta a vida do paciente é a dor, pois se torna parte do seu dia a dia, não somente a dor física que é referida, mas, também a emocional, ao ver outras crianças brincando e saber que não pode fazer o mesmo para evitar as crises dolorosas. Diante disto, a internação é algo inevitável e por se tornar constante é importante que o enfermeiro mostre empatia não somente na situação clínica, mas também sócias emocionais e familiares, que devem ser vistas de acordo com a especificidade de cada situação.

Observou-se também, que os cuidadores possuem um conhecimento simplório sobre os cuidados necessários para com os pacientes falcêmicos, por outro lado, ficou evidente que a maioria dos cuidadores não possuem um ampla concepção sobre a patologia.

Durante o estudo foi notado que uma das crianças não faz o tratamento adequando, mas de uma forma totalmente empírica, o que trás prejuízo para saúde do portador, neste caso é importante que o profissional de enfermagem que trabalha na Unidade Básica de Saúde - UBS da localidade, faça uma busca ativa, pois é importante que a cuidadora se sinta assistida e incluída. Desta forma, o enfermeiro leva orientação a respeito da siclemia e cuidados importantes para o paciente.

Comprende-se que o enfermeiro, assim como os demais profissionais de saúde, são considerados instrumentos fundamentais para com o cuidado com os pacientes falcêmicos, pois estabelecem estratégias para que ocorra uma participação ativa no autocuidado, orientações terapêuticas que possam estimular a manutenção do tratamento, bem como ações educativas que possam influenciar na promoção à saúde, podendo ter como meta principal a melhoria da qualidade de vida dos pacientes, reduzindo desta forma, as complicações agudas e crônicas proporcionadas ao seu meio físico, emocianal e social. Além de ser necessário, que estes profissionais conheçam o portador de AF, bem como sua trajetória de vida, para que ocorra uma maior interação com os envolvidos neste processo, em razão da cronicidade desencadeada pela doença e sua alta exigência de cuidados que são requeridos na vivência dos portadores.

Em vista disto, é de extrema importância a realização de novos estudos abrangendo diversas áreas da patologia e as inúmeras complicações que propiciam para o portador e sua família, sendo de aspecto social, emocional e financeiro.

\section{Referências}

Araújo, F. C. et al. (2020). Diagnóstico precoce da anemia falciforme: uma revisão da literatura. Research, Society and Development, 9(4), e79942516e79942516. 
Research, Society and Development, v. 10, n. 7, e24010716450, 2021

(CC BY 4.0) | ISSN 2525-3409 | DOI: http://dx.doi.org/10.33448/rsd-v10i7.16450

Ataíde, C. A., \& Ricas, J. (2017). O enfrentamento do diagnóstico da doença falciforme: Desafios e perspectivas vivenciadas pela família. Scientia Plena, 13(5).

Brito, T. S. (2018). Avaliação da qualidade de vida de pessoas portadoras da doença falciforme: uma revisão integrativa.

Carvalho, E. M. M. S. et al. (2016). < b> O cuidado de enfermagem à pessoa com doença falciforme em unidade de emergência/Nursing care to people suffering with sickle cell disease in emergency unit 〈b〉. Ciência, Cuidado e Saúde, 15(2), 328-335.

Ministério da Saúde. (2015). Doença falciforme: conhecer para cuidar.

Ministério da Saúde. (2014a). Doença falciforme: o que deve saber sobre herança genética. http://bvsms.saude.gov.br/bvs/publicacoes/http://bvsms.s aude.gov. br/bvs/ publicacoes/d oenca_falciforme_deve_saber_sobre_heranca.pdf_falciforme_diretriz es_basicas_linha_cuidado.pdf.

Ministério da Saúde. (2015b). Doença falciforme: diretrizes básicas da linha de cuidado. http://bvsms.saude.gov.br/bvs/publicacoes/doenca falciforme_diretrizes_basicas_lin ha_cuidado.pdf.

Ministério da Saúde. (2015c). Traço falciforme: consenso brasileiro sobre atividades esportivas e militares..

Felix, A. A., Souza, H. M., \& Ribeiro, S. B. F. (2010). Aspectos epidemiológicos e sociais da doença falciforme. Revista brasileira de hematologia e hemoterapia, 32(3), 203-208.

Ferreira, H. P. et al. (2012). O impacto da doença crônica no cuidador. Revista Brasileira de Clínica Médica, 10(4), 278-284.

Figueiredo, A. K. B. et al. (2014). Anemia falciforme: abordagem diagnóstica laboratorial. Revista de Ciências da Saúde Nova Esperança, $12(1), 98-105$.

Fonseca, G. (2019). Anemia Falciforme: O Que é anemia falciforme e de onde vem este nome. https://drauziovarella.uol.com.br/videos/entrevistas-emvideo/anemia-falciforme- guilherme-fonseca/.

Gesteira, E. C. R., Bousso, R. S., \& Rodarte, A. C. (2016). Uma reflexão sobre o manejo familiar da criança com doença falciforme. Revista de Enfermagem do Centro-Oeste Mineiro, 6(3).

Guimarães, T. M. R., Miranda, W. L., \& Tavares, M. F . (2009). O cotidiano das famílias de crianças e adolescentes portadores de anemia falciforme. Rev bras hematol hemoter, 31(1), 9-14

Gonçalves, I. D., Cordeiro, M. M., \& Da Silva, Z. B. (2018). Anemia falciforme e o comprometimento da aprendizagem em crianças e jovens no período escolar. Revista de Ensino, Educação e Ciências Humanas, 19(2), 245-251.

Leite, M. F. et al. (2015). Impacto na vida de mães cuidadoras de crianças com doença crônica [Impact on mothers' lives of caring for children with chronic illnesses]. Revista Enfermagem UERJ, 23(4), 501-506.

Lessa, A. B. S. L. (2012). Cuidados prestados pelas mães aos filhos com doença falciforme: superando desafios.

Lima, L. et al. (2019). Qualidade de vida dos portadores de doença falciforme. Journal of Nursing UFPE/Revista de Enfermagem UFPE, 13(2).

Lopez, M., \& Stuhler, G. D. (2008). Atendimento psicológico a mães de crianças com doença crônica: relato de experiência. Psicol. Argum, 26(55), 341 -347.

Pimentel, B.T. (2019). "Essa anemiazinha": experiências de pais/responsáveis por crianças e adolescentes com a doença falciforme.

Rodrigues, F. M. S. et al. (2018). Terapia medicamentosa no domicílio: experiências de mães de crianças e adolescentes com anemia falciforme. Cogitare Enfermagem, 23(2).

Rosa, J. R., \& Martin, S. T. F. (2019). Desenvolvimento do psiquismo e anemia falciforme: o impacto do adoecimento no exercício das atividades vitais. Interação em Psicologia, 23(2).

Silva, A. H. et al. (2013). Cotidiano da família que experiência a condição crônica por anemia falciforme. Revista Eletrônica de Enfermagem, 15(2).

Vieira, A. G. (2016). Prevalência do traço falciforme em doadores de sangue do Distrito Federal. 